\title{
An Assessment of Sustainable Development in the South Central Coast of Vietnam During the Period from 2010 to 2016
}

\author{
Le Thi Ly ${ }^{1}$, Nguyen Tai Tue ${ }^{1,2, *}$, Lam Tuan Manh ${ }^{1}$, Mai Trong Nhuan ${ }^{1,2}$ \\ ${ }^{1}$ VNU Key Laboratory of Geoenvironment and Climate change Response, 334 Nguyen Trai, Hanoi, Vietnam \\ ${ }^{2}$ Faculty of Geology, VNU University of Science, 334 Nguyen Trai, Hanoi, Vietnam
}

Received 22 March 2019

Revised 18 June 2019; Accepted 12 July 2019

\begin{abstract}
In the context of global change, the rapidly increase of socio-economic development can trigger the negative impacts on coastal resources, environment and ecosystems, causing the deterioration of the sustainable system. Vietnam is one of the most vulnerable countries to climate change. Of which, the South Central Coast (SCC) is a highly vulnerable area to climate extreme events and sea level rise. This study aimed to build a theoretical framework for evaluating the level of sustainable development in the SCC. By using Delphi method, Interpolation method and Evaluation method, this study proposed a set of indicators, which consists of 32 indicators of the four dimensions (Economic; Social; Environmental; Infrastructure and Governance) in order to evaluate the sustainable development index (SDI) of the SCC provinces. Results show that the SDI had an increasing tendency from 2010 to 2016. In general, Da Nang is the capital of the region and the SDI was highest which increased from 0.38 in 2010 to 0.61 in 2016 through the development of economic, infrastructure and urban governance dimensions. In contrast, during the survey, Binh Dinh and Phu Yen's SDI were still lower than other provinces. Results suggested that it is necessary to enhance the policy and planning to implement the sustainable development goals together with the economy, society, environment and infrastructure development. The sustainable development indicators can potentially contribute to apply to monitor the sustainable development in other coastal regions in Vietnam.
\end{abstract}

Keywords: Sustainable development, Indicators, Climate change, South Central Coast, Vietnam.

\footnotetext{
* Corresponding author.

E-mail address: tuenguyentai@ hus.edu.vn

https://doi.org/10.25073/2588-1094/vnuees.4377
} 


\section{Introduction}

After the Brundtland report "Our Common Future" in 1986, the sustainable development has become a key concept for countries in the world to build their views, planning and solutions to development issues. The process of sustainable development requires a close, reasonable and harmonious development between economy, society, and environment and proactive respond to climate change [1]. Climate change is increasingly unpredictable and severely damaging to the ecological environment and human life. Therefore, sustainable development is among the top priorities of the human being, especially for Vietnam - one of the most vulnerable countries to climate change. Towards sustainable development, minimizing climate change impacts, researchers have used a variety of approaches to sustainable development across a range of areas. To date, several assessment methods have been proposed and applied in order to establish the Sustainable development indicators (SIs) to measure the sustainable development, including DPSIR framework [2], Rapfish method [3], socio-ecological system framework [4], Z-score technique [5], Delphi method [6-8]. Recognizing the need for sustainability assessment in Vietnam, the Prime Minister issued a statistical indicator system with 28 economic-social-environmental indicators combined with more than 15 specific indicators for specific regions including Northern midlands and mountainous, Delta, Coastal, Centrally-run city and Countryside in Decision No. 2157/QD-TTg.

South Central Coast (SCC) consists of 8 provinces and municipalities, namely Da Nang, Quang Nam, Quang Ngai, Binh Dinh, Phu Yen, Khanh Hoa, Ninh Thuan, Binh Thuan province. Being recognized as a connection between the North Central Coast and the South East, the SCC has an important strategic role in the development of Vietnam economy. However, the area is highly impacted by natural disasters and extreme weather events [9]. Climate change and disasters have significantly caused the damage on the economy and society of the region. Therefore, the establishment of the SIs is necessary to develop sustainable socioeconomic development strategies, proactive response to climate change and protection of the environment [9]. However, there are some difficulties to assess the level of sustainable development of the province based on the set of indicators of Decision No. 2157, because many indicators are difficult to collect data, measurement, affecting the results of the overall sustainable development indicator in each locality. Therefore, the purpose of this study aims to build the SIs for the coastal area of Vietnam and apply the SIs to evaluate the sustainable development level for the SCC.

\section{Study area}

The SCC is located in favorable geographical position - near Ho Chi Minh City and South East key economic triangle and also the gateway to the Central Highlands (Fig.1). All provinces in the SCC are located back of Truong Son range and in front of East Sea. It covers an area of 44.54 thousand square kilometers, accounting for $13.44 \%$ of the country. The total population was 9.247 million people in 2016, accounting for $10 \%$ of country's population [10]. There are two offshore archipelagos: Hoang Sa (Da Nang province) and Truong Sa (Khanh Hoa province). The SCC concentrates several key economic zones along the coast of Da Nang, Nha Trang, Quy Nhon, and Phan Thiet, which has a strategic role in the development of Vietnam economy. In addition, the harmonious combination between seas and mountains, the ancient relics, etc. create the big advantage in tourism for the SCC. 


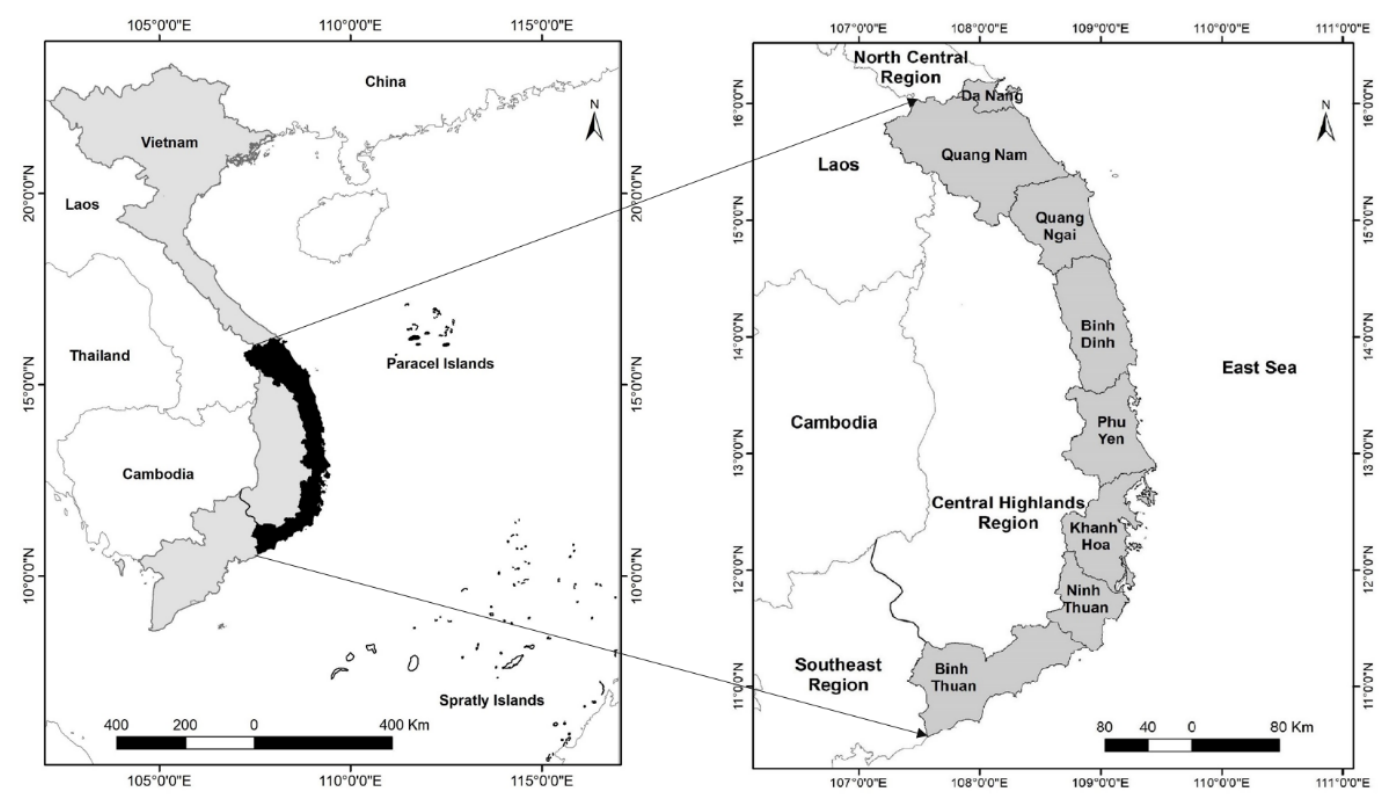

Fig. 1. Geographical location and administrative map of the SCC region.

Along with the potential, the region is one of two regions in Vietnam which have the harshest climate in comparison with other places. Annually, the SCC undergoes many natural disasters like hurricanes, floods and droughts that has big effects on agricultural production. In addition, socio-economic development is considerably constrained and locally sustainable development goals are difficult to meet because of excessive population growth, inequality distribution and increased environmental pollution.

\section{Process of implementation and methodology}

\subsection{Establishment of indicator set for sustainable development assessment}

The set of indicators to assess the sustainable development of the SCC during the period 20102016 is inherited from earlier studies of UNDP [11, 12], United Kingdom [13], Hong Kong, Malaysia [14], Wales [15] and of Vietnam sustainable development, including Decision No. 2157/QD-TTg [16] Decision No. 432/QDTTg [17]. Through the qualifiers with the Delphi method by consultation with experts, the proposed set of indicators for sustainable development of SCC provinces in the period of 2010-2016, including 32 indicators of four dimensions (economic; social; environmental; infrastructure and urban governance).

After establishing the set of indicators and collecting the necessary data, standardize and calculate the indicators according to the selected formula. Final calculations will help the SCC provinces to track the sustainable development over the years, compare, monitor, and adjust the plan accordingly and make decisions to guide the achievement of the goals of sustainable development (Fig. 2). The contents of the SIs for SCC during the period 2010-2016 are shown in Table 1. A set of SIs is developed to assess the sustainable socio-economic development, but still ensures environmental quality, sustainable management. Therefore, four basic dimensions are proposed, inheriting the contents and dimensions of sustainable development goals (SDGs) of the United Nations as well as Vietnam. The selected core dimensions are Economic; Social; Environmental; Infrastructure and Urban Governance along with the sub-dimensions and corresponding indicators that should be ensured three criteria: understandability, representativeness for the provinces and data that can be collected [18]. 


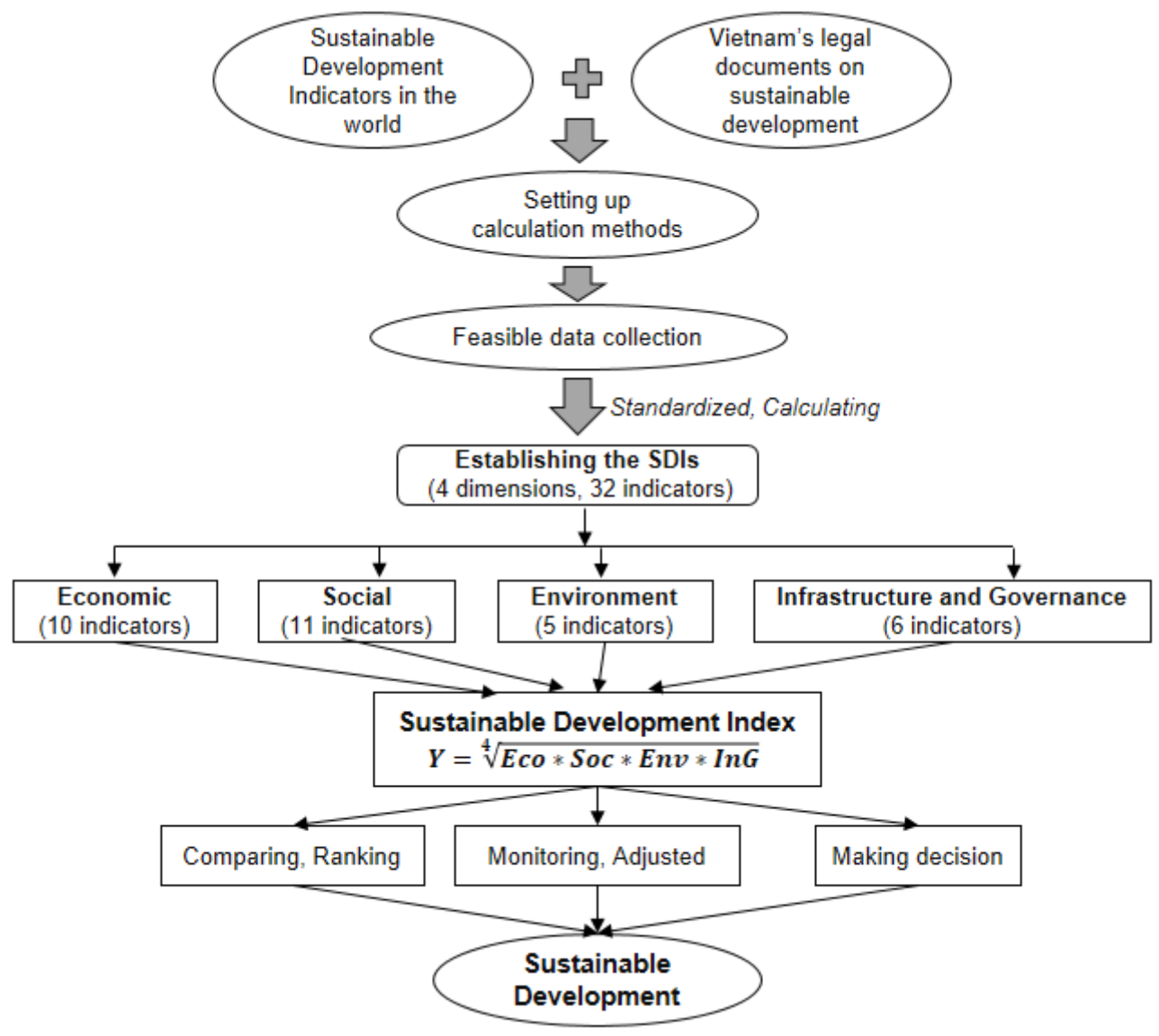

Fig. 2. Framework for assessing sustainable development.

\subsection{Scoring methods}

The SIs contain two types of indicators [19], consisting of the positive indicators (indicator values positively affect the integrated index) and negative indicators (indicator values inversely affect to the integrated index). For instance, with some positive indicators, such as annual GRDP growth rate, monthly average income, total export/import output, rate of trained workers, population growth rate, forest coverage rate, provincial competitiveness index and so on (Table1), when the values of these indicators increase it prove for the growth of economysocial-environment-governance dimension and will lead to the increase of integrated index. Whereas, the increase of the values of some negative indicators, such as unemployment rate, poverty rate, forest area is burnt and destroyed and so on (Table 1) will cause negative impact on the economics, environment, and social pillars and consequently decrease the integrated index. The positive and negative indicators is presented in Table 1.

Different types of indicators have different variable values and unit heterogeneity. Therefore, to calculate the indicators and use the data of that indicators in the calculation, this study calibrated and standardized the same range of values from 0 to 1 [20]. The higher the value calculated, the closer the province/city to sustainable development. The Sis are calculated based on the following two methods: (1) standardized according to min-max normalization theory (equations 1 and 2), (2) 
scaled on a scale of 0-1. Each indicator type applied in different equations as follows:

For positive indicators, the following formula is applied:

$$
I_{\text {positive }}=\frac{X i-\operatorname{MinX} X_{i}}{\operatorname{MaxX} X_{i}-\operatorname{MinX} X_{i}} \quad \text { (Eq.1) [21] }
$$

For negative indicators, the following formula is applied:

$$
I_{\text {negative }}=\frac{\operatorname{MaxX}_{i}-X i}{\operatorname{Max} X_{i}-\operatorname{MinX} X_{i}} \quad \text { (Eq.2) [21] }
$$

In which, $\mathrm{X}$ is a value of indicator $\mathrm{X}$; MaxX and MinX denotes for the maximum and minimum scaled values of indicator $X$, respectively. In particular, the Max and Min values of each indicator are determined based on the set of statistics in the stage of the study area or the expected value. This formula was used to assess the environmental quality of coastal areas for planning and management by Antonio Cendrero in 1997 [21].

\begin{tabular}{|c|c|c|c|c|}
\hline Dimensions & Sub-Dimensions & Indicators & Sources & $\begin{array}{l}\text { Scoring } \\
\text { methods }\end{array}$ \\
\hline \multirow{10}{*}{ Economic } & \multirow{2}{*}{$\begin{array}{l}\text { Economic } \\
\text { development }\end{array}$} & Annual GRDP growth rate $(+)$ & {$[10,23]$} & Eq.1 \\
\hline & & Monthly average income (+) & {$[10,23]$} & Eq.1 \\
\hline & \multirow{3}{*}{ Sustainable finance } & Incremental Capital Output Ratio (ICOR) (+) & {$[10,23]$} & Eq.1 \\
\hline & & Rate of local budget revenue/expenditure (+) & {$[10,23]$} & Eq.1 \\
\hline & & Rate of budget overspending/GRDP (-) & {$[10,23]$} & Eq. 2 \\
\hline & \multirow{3}{*}{ Labor } & Unemployment rate (-) & {$[10,23]$} & Eq.2 \\
\hline & & Rate of trained workers $(+)$ & {$[10,23]$} & Eq.1 \\
\hline & & Labor productivity $(+)$ & {$[10,23]$} & Eq.1 \\
\hline & \multirow{2}{*}{ Export - Import } & Total export/import output (+) & {$[10,23]$} & Eq.1 \\
\hline & & Export/import Rate $(+)$ & {$[10,23]$} & Eq.1 \\
\hline \multirow{11}{*}{ Social } & \multirow[t]{2}{*}{ Population } & Population growth rate $(+)$ & {$[10,23]$} & Eq. 1 \\
\hline & & Population density (-) & {$[24]$} & Eq. 2 \\
\hline & \multirow{3}{*}{$\begin{array}{l}\text { Poverty and } \\
\text { inequality in } \\
\text { income distribution }\end{array}$} & Poverty rate $(-)$ & {$[10,23]$} & Eq.2 \\
\hline & & GINI coefficient $(+)$ & {$[10,23]$} & Eq.1 \\
\hline & & Number of doctors per 10000 inhabitants (+) & {$[10,23]$} & Eq.1 \\
\hline & \multirow[t]{2}{*}{ Medical } & $\begin{array}{l}\text { Rate of under-one-year children fully } \\
\text { vaccinated }(+)\end{array}$ & {$[10,23]$} & Eq.1 \\
\hline & & Under-five-malnutrition rate $(+)$ & {$[10,23]$} & Eq.1 \\
\hline & \multirow{3}{*}{ Education } & Enrolment rate at right age $(+)$ & {$[10,23]$} & Eq.1 \\
\hline & & $\begin{array}{l}\text { Percentage of literate population aged } 15 \\
\text { and over }(+)\end{array}$ & {$[10,23]$} & Eq.1 \\
\hline & & High school graduation rate $(+)$ & {$[10,23]$} & Eq.1 \\
\hline & Culture - Sports & $\begin{array}{l}\text { Proportion of local budget expenditures } \\
\text { for cultural-sport activities }(+)\end{array}$ & {$[10,23]$} & Eq.1 \\
\hline \multirow{4}{*}{ Environmental } & $\begin{array}{l}\text { Water quality/ } \\
\text { water reserves }\end{array}$ & $\begin{array}{l}\text { Percentage of population using } \\
\text { hygienic water }(+)\end{array}$ & {$[10,23]$} & Eq.1 \\
\hline & Natural resources & $\begin{array}{l}\text { Forest coverage rate }(+) \\
\text { Forest area is burnt and destroyed }(-)\end{array}$ & $\begin{array}{l}{[10,23]} \\
{[10,23]}\end{array}$ & $\begin{array}{l}\text { Eq.1 } \\
\text { Eq. } 2\end{array}$ \\
\hline & \multirow{2}{*}{$\begin{array}{l}\text { Environmental } \\
\text { Management }\end{array}$} & $\begin{array}{l}\text { Number of employees engaged } \\
\text { in waste collection }(-)\end{array}$ & {$[10,23]$} & Eq.2 \\
\hline & & $\begin{array}{l}\text { Number of enterprises engaged } \\
\text { in waste collection (-) }\end{array}$ & {$[10,23]$} & Eq.2 \\
\hline
\end{tabular}

Table 1. Sustainable development indicators for SCC provinces 


\begin{tabular}{|c|c|c|c|c|}
\hline \multirow{6}{*}{$\begin{array}{l}\text { Infrastructure } \\
\text { and Urban } \\
\text { Governance }\end{array}$} & Health services & $\begin{array}{l}\text { Number of hospital beds per } 10000 \\
\text { inhabitants }(+)\end{array}$ & {$[10,23]$} & Eq. 1 \\
\hline & Electricity & $\begin{array}{l}\text { Percentage of households using } \\
\text { domestic electricity }(+)\end{array}$ & {$[10,23]$} & Eq.1 \\
\hline & Information and & $\begin{array}{l}\text { Number of internet subscribers } \\
\text { per } 100 \text { inhabitants }(+)\end{array}$ & {$[10,23]$} & Eq.1 \\
\hline & $\begin{array}{l}\text { communication } \\
\text { technology }\end{array}$ & $\begin{array}{l}\text { Number of telephone subscribers } \\
\text { per } 100 \text { inhabitants }(+)\end{array}$ & {$[10,23]$} & Eq. 1 \\
\hline & Urban Security & $\begin{array}{l}\text { Number of people died by traffic } \\
\text { accident per } 10000 \text { inhabitants }(+)\end{array}$ & {$[10,23]$} & Eq.1 \\
\hline & $\begin{array}{l}\text { Quality of economic } \\
\text { and business } \\
\text { environment } \\
\text { governance }\end{array}$ & Provincial Competitiveness Index (PCI) (+) & {$[10,23]$} & Eq.1 \\
\hline
\end{tabular}

After standardizing the indicators, the Simple geometric mean method (unweighted) was used to calculate the Integrated sustainable development index (SDI). This method will level out, offset the difference in the value of the indicators, thus giving the most representative value for the research problem [22].

During the data collection, there are some indicators collected only for some years such as: monthly average income per capita, percentage of households using domestic electricity, percentage of population using hygienic water, etc. in some provinces only the value of the 2010, 2012, 2014, 2016 and the indicators tend to increase or decrease continuously, so the interpolation method was selected by the team to find the missing values. Interpolation method can be easily calculated using some of the basic functions in Microsoft Excel such as FORECAST, TREND.

After the indicators are normalized to $0-1$, the SDI of the respective 4 dimensions (Economic; Social; Environmental; infrastructure and governance) is calculated according to the Eq. 3:

$$
\mathrm{I}_{\text {Dimension }}=\sqrt[n]{\prod_{i=1}^{n} I_{i}} \quad \text { (Eq.3) }
$$

Where, $\mathrm{I}_{\mathrm{Eco}}$ (Index of Economic dimension), $\mathrm{I}_{\mathrm{So}}$ (Index of Social dimension), $\mathrm{I}_{\mathrm{En}}$ (Index of Environmental dimension), $\mathrm{I}_{\mathrm{InG}}$ (Index of Infrastructure and Governance dimension). Once the indicators of the four dimensions capacities have been identified as well as respective indicators of each dimension, the local SDI is calculated by the formula:

$$
Y=\sqrt[4]{E c o * \operatorname{Soc} * E n v * \operatorname{InG}} \quad \text { (Eq.4) }
$$

The integrated SDI $(\mathrm{Y})$ is closer to 1 meaning the development more sustainable and vice versa $[22,25]$.

\section{Results and discussion}

\subsection{Results of economic sustainable development index}

Results from the economic dimension indicate that from 2010 to $2016 \mathrm{Da}$ Nang was always the leading province for the economic SDI in the SCC, reaching the highest of 0.64 in 2016, followed by Khanh Hoa at 0.56 (Fig. 3). The result also reflected the status of economic development of these localities. Da Nang and Khanh Hoa are known as the two largest economic centers, which established industrial zones and bustling economic activities attracting the number of high skilled workers. Meanwhile, Ninh Thuan always had the lowest economic SDI during the period of the survey, the main reason is because of unexpected change in climatic condition that had a big impact on agriculture activities. With other provinces, Economic SDI increased year by year. 


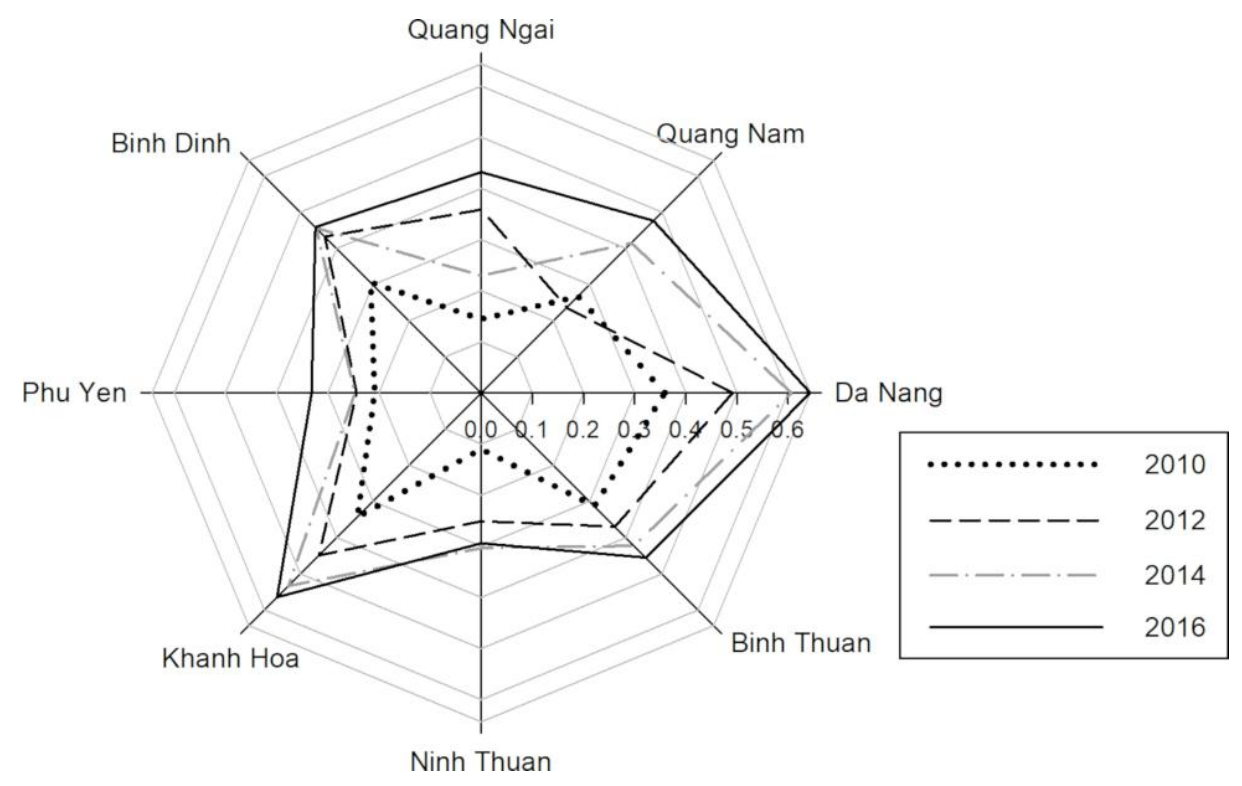

Fig. 3. Economic SDI in the SCC from 2010 to 2016.

4.2. Results of social sustainable development index

In term of social dimension, it shows that quality of life in the SCC was enhanced as the Social SDI augmented steadily over the years. That was shown by positive changes in some indicators of the social dimension such as poverty rate and rate of under-one-year children fully vaccinated and under-five-malnutrition rate.

Da Nang always had the lowest poverty rate in the region (Fig. 4), which rapidly decreased from $5.1 \%$ in 2010 to $0.5 \%$ in 2016. This encouraging result has been achieved through the fact that this city seriously focused, creatively implemented and widely propagated the poverty reduction policies, supporting policies for the poor according to Decisions No. 367/QD-UBND, Decision No.19/QD-UBND and Decision No.48/QD-UBND [26].

Furthermore, at the same time in SCC, Quang Nam and Quang Ngai also obtained positive results in reducing poverty rates. Quang Nam diminished $13.08 \%$ (from $24.18 \%$ to $11.1 \%$ ) and Quang Ngai also decreased $8.5 \%$ (from $23.92 \%$ to $13.06 \%$ ) in the last 7 years of $2010-2016$ (Fig. 4).

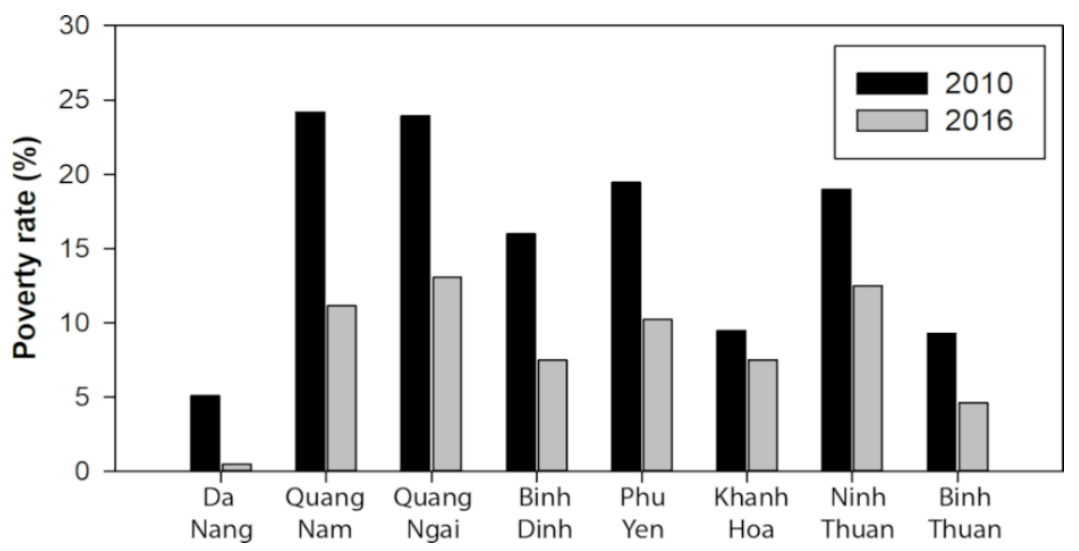

Fig. 4. Poverty rate of the SCC provinces. Source:[10] 
Table 2. Social SDI of the SCC provinces from 2010 to 2016

\begin{tabular}{lll}
\hline \multicolumn{1}{c}{ Province } & 2010 & 2016 \\
\hline Da Nang & 0.454 & 0.464 \\
Quang Nam & 0.398 & 0.641 \\
Quang Ngai & 0.357 & 0.576 \\
Binh Dinh & 0.531 & 0.666 \\
Phu Yen & 0.468 & 0.561 \\
Khanh Hoa & 0.469 & 0.633 \\
Ninh Thuan & 0.330 & 0.579 \\
Binh Thuan & 0.450 & 0.628 \\
\hline
\end{tabular}

The Social SDI highly depends on changes in education and health such as the under-five malnutrition rate, the number of doctors per 10000 inhabitants. In general, the Social SDI of the provinces in the SCC had a tendency to change positively year by year, distribute more equally and reach the highest values in the 3 provinces namely Quang Nam, Binh Dinh, Binh Thuan in 2016 (Table 2).

\subsection{Results of environmental sustainable development indicators}

The Environmental SDI of the SCC provinces in the period of 2010 - 2016 changed remarkably. By calculating indicators in the environmental dimension, it shows that Khanh Hoa, Binh Thuan and Da Nang reached the high scores of more than 0.5 in recent years (Fig. 6). In the period 2010-2016, two provinces Quang Ngai and Binh Thuan reported a remarkable increase in the SDI of the environment from 0.23 and 0.24 to 0.48 and 0.59 respectively (Fig.5). These two localities also had better forest protection policies so that the forest cover area increased year by year (Fig.5).

In term of natural resource indicators, the higher the forest coverage rate and implementation of forest protection measures to restrict fired and destroyed forest area, the healthier environment is. For example, Ninh Thuan province made efforts to decrease deforested area to an extremely low-level only 0.9 ha in 2016 and forest cover rate in 2016 was $45.06 \%$, resulting in extending the forest coverage rate in here (Fig.5).

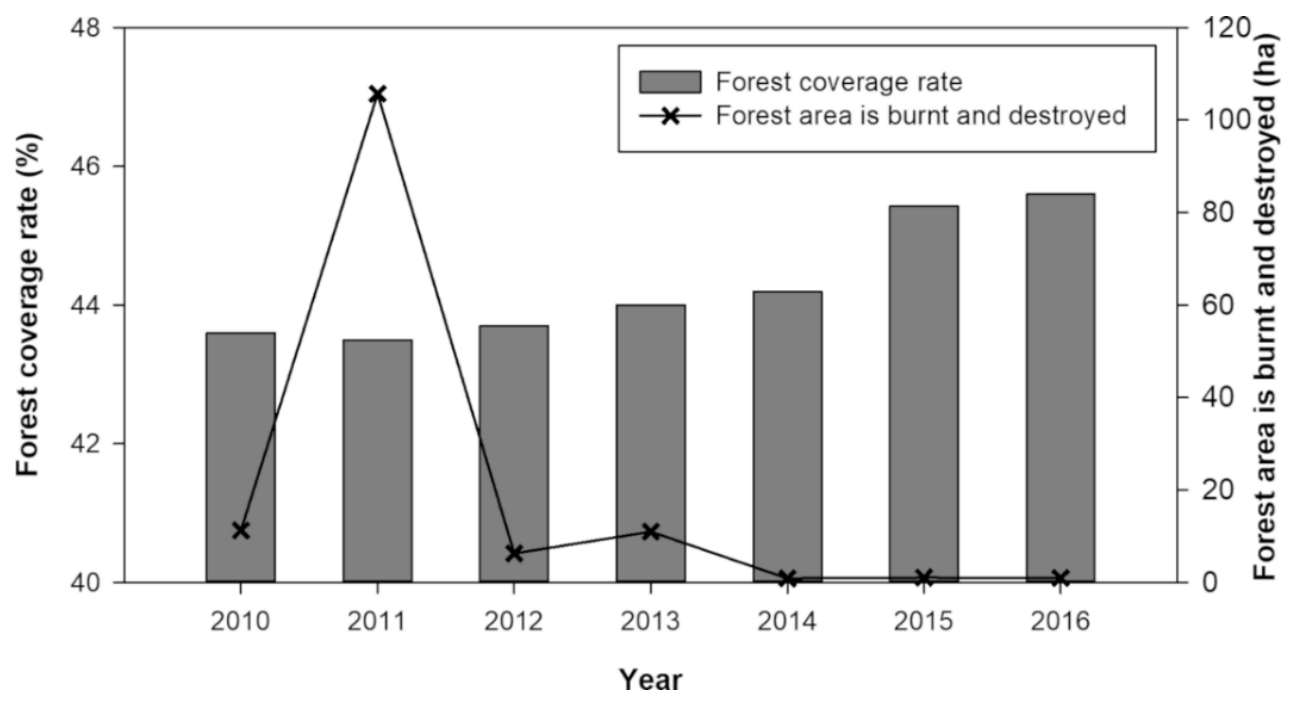

Fig. 5. Forest coverage rate and Forest area is burnt and destroyed in Ninh Thuan from 2010 to 2016. 


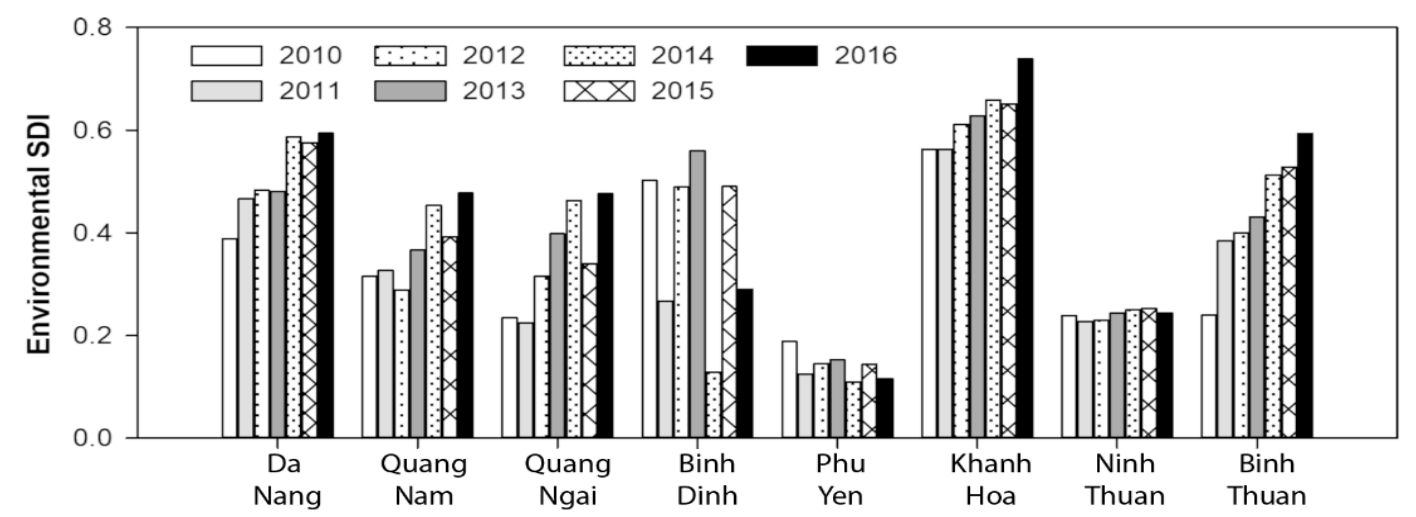

Fig. 6. Environmental SDI of the SCC provinces from 2010 to 2016. Source:[10]

4.4. Results of infrastructure and governance sustainable development index

The infrastructure development level impacts mainly on the development level of the country and the investment in infrastructure development prioritized in many developing countries. Da Nang, an economic center of the region and country always is the leading province for Infrastructure and Governance SDI, was 0.78 in 2016, while this figure for Ninh Thuan was just 0.22 (Fig.7). There was a big change in the Infrastructure and Governance SDI in all provinces especially Da Nang (0.31 in 2010 to 0.78 in 2016), Quang Ngai (0.27 in 2010 to 0.46 in 2016).

Moreover, Da Nang was the leading province for quality of governance. One reason for this change was that the local authorities focused on management, especially the Provincial Competitiveness Index (PCI) to highly rank on the national charts. According to the report of Vietnam Chamber of Commerce and Industry (VCCI), since 2010, Da Nang always ranked the highest Provincial Competitiveness Index (PCI) in Vietnam (Table 3). It is worthy that the city is known as a developed and civilized city which has judicious policies and orientations from the regulatory authorities. In addition, by the effort, Quang Ngai and Khanh Hoa had remarkable increased from the ranking $55^{\text {th }}$ and $40^{\text {th }}$ to $26^{\text {th }}$ and $24^{\text {th }}$ out of 63 provinces in the country respectively. This reflects that their quality of economic governance and building a favorable business environment for private-enterprise development is effective comparing with their potential and benefits [27].

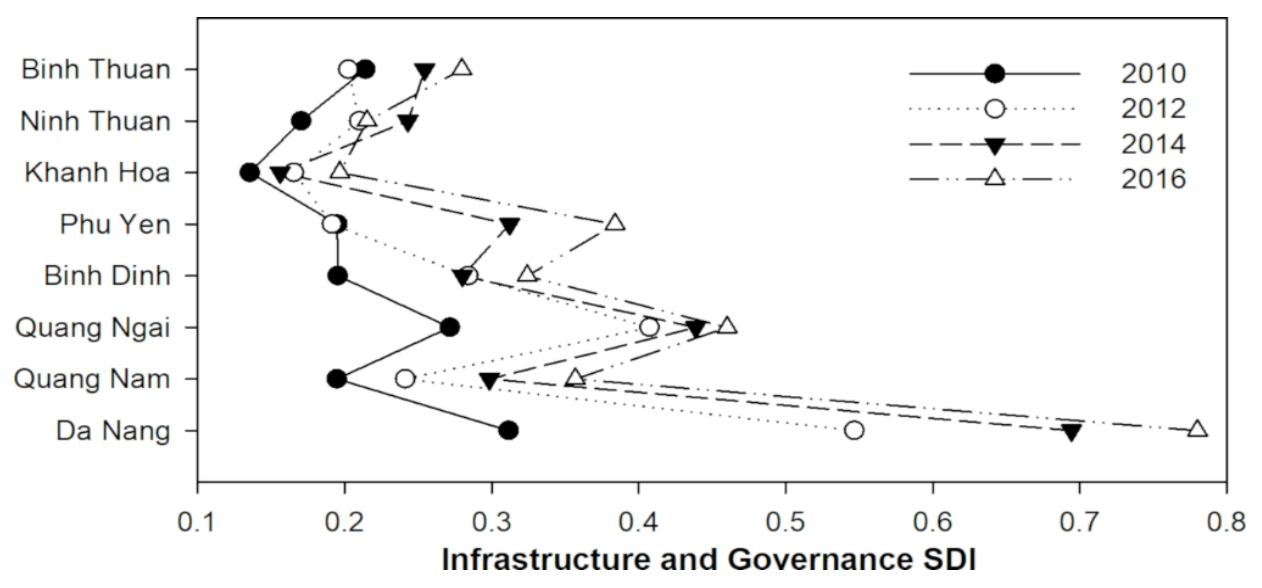

Fig. 7. Infrastructure and Governance SDI of the SCC provinces from 2010 to 2016. 
Table 3. PCI and the ranking of the SCC provinces in Vietnam from 2010 to 2016

\begin{tabular}{lllll}
\hline Province & 2010 & Ranking & 2016 & Ranking \\
\hline Da Nang & 69.77 & 1 & 70.00 & 1 \\
Quang Nam & 59.34 & 26 & 61.17 & 10 \\
Quang Ngai & 52.21 & 55 & 59.06 & 26 \\
Binh Dinh & 60.37 & 20 & 60.24 & 18 \\
Phu Yen & 58.18 & 31 & 56.93 & 51 \\
Khanh Hoa & 56.75 & 40 & 59.59 & 24 \\
Ninh Thuan & 56.61 & 41 & 57.19 & 49 \\
Binh Thuan & 58.45 & 28 & 58.20 & 32 \\
\hline \multicolumn{5}{c}{ Sources: [28] }
\end{tabular}

4.5. Results of integrated sustainable development index

With the positive changes from the index of each dimensions over the years, the SDI of SCC provinces has improved considerably at all dimensions (Fig. 8, Fig. 9).

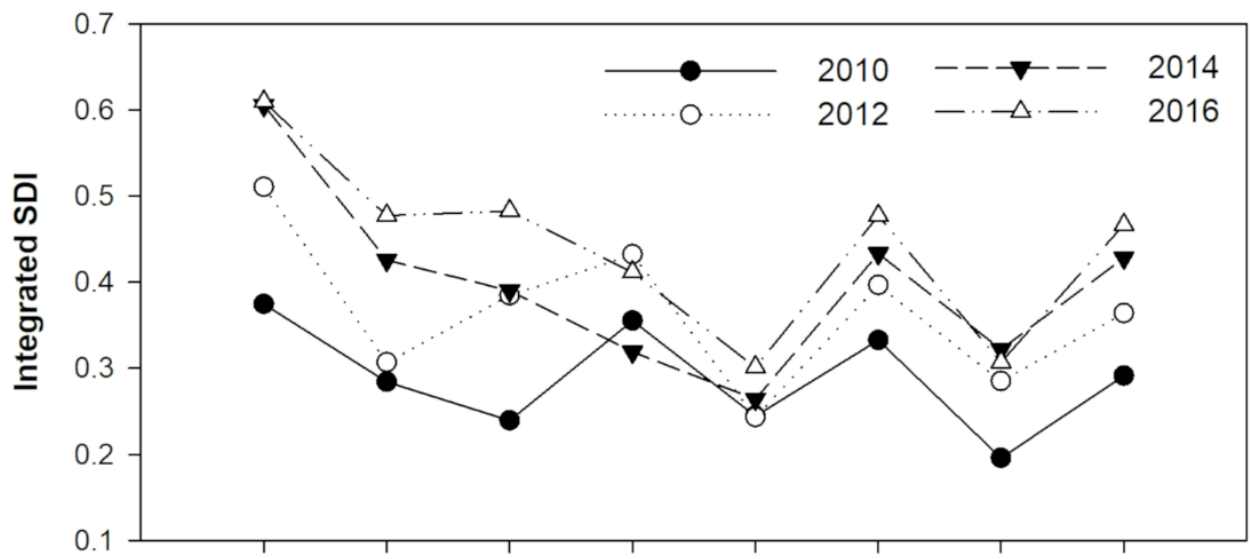

Fig. 8. Integrated SDI in SCC Provinces from 2010 to 2016.

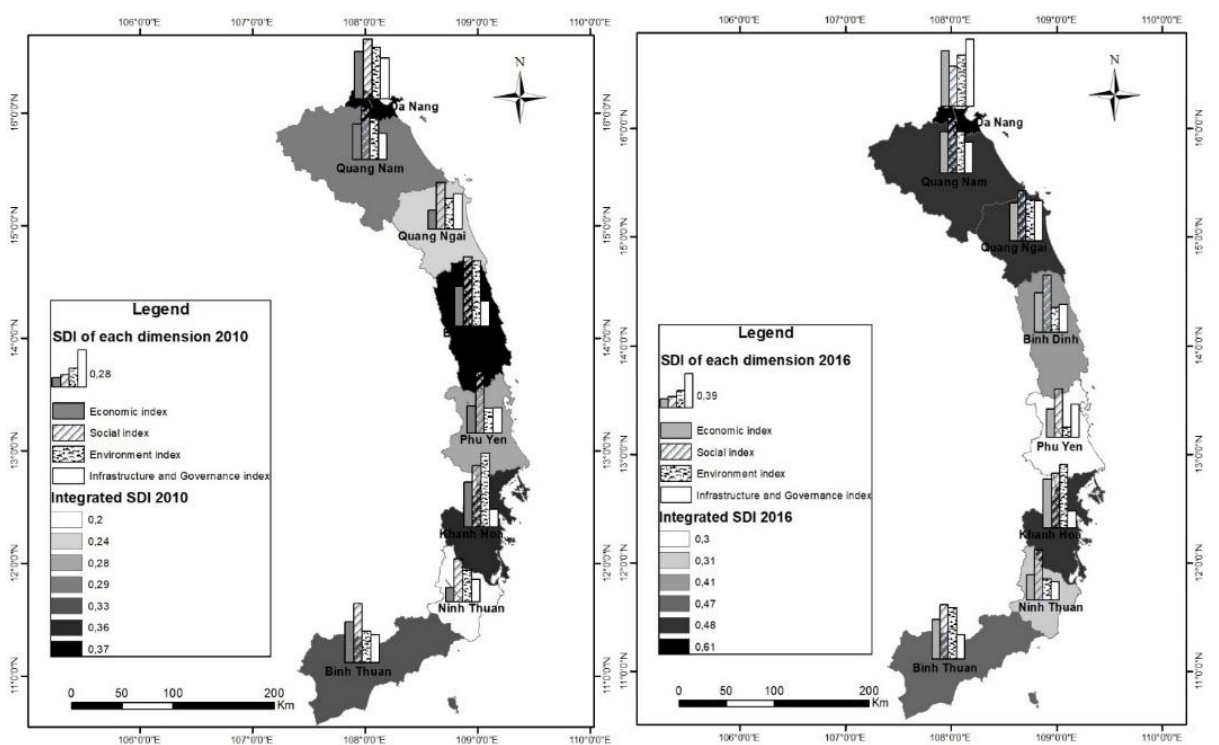

Fig. 9. Comparison the SDI of each dimension and integrated SDI in the SCC in period of 2010-2016. 
The highest Integrated SDI provinces was Da Nang (reaching 0.61 in 2016), followed by Khanh Hoa, Quang Ngai, Quang Nam (reaching 0.48 in 2016) (Fig. 8. ). By contrast, Phu Yen and Ninh Thuan always obtained the lowest results. This also reflects the status of socio-economic development as well as the efforts to manage environmental resources.

In general, Da Nang is the capital of the region and scores was higher than the other areas such as for economic $(0.35$ in 2010 and 0.6431 in 2016) infrastructure and governance $(0.31$ in 2010 and 0.78 in 2016) but lower for social (0.464 in 2016) and environmental (0.59 in 2016) (Fig. 9). While, although Binh Dinh reached a quite low economic SDI, which ranked the forth in 2010 and still remain to 2016 but it reached the highest scores for Social (0.66 in $2016)$ and environmental (0.5 in 2010) in SCC.

\section{Conclusion and research orientation in the future}

A total of 32 indicators and 4 dimensions including Economic; Social; Environmental; Infrastructure and Urban governance are proposed to assess the sustainable development of the SCC provinces. The study also identified the absolute methodology in order to set indicators as well as calculate formulas and successfully indexed the SDI in the SCC provinces for the period 2010 to 2016. SIs remarkably depend on the choice of targets, maximum and minimum values in each indicator and dimension described above. It indicated that, in the period 2010 to 2016 the provinces in the SCC developed in a positive way. The SDI in 2016 was higher than in 2010 for all regions. Particularly, highly developed group included Da Nang, Binh Dinh, Khanh Hoa, Binh Thuan, while the low value group was 2 provinces, including Phu Yen and Ninh Thuan.

In order to improve the SDI in the coming years, it is necessary to investigate and adjust the indicators toward socio-economic development targets and environmental resource management to ensure infrastructure development and enhance governance capacity, develop comprehensive dimensions of sustainable development assessments. The proposal indicators and the methodology are able to calculate the SDI for other provinces, cities and case studies with similar characteristics. The approach to the calculation method and the sustainable development assessment discussed above is able to use for monitoring the status of sustainable development in local and to identify remaining issues in the implementation process. As a result, proposed solutions to orient and change plan of the region to quickly increase the SDI should be taken into implementation.

This results will be the premise for further investigations which will be based on the proportion in accordance with the indicators and dimensions. In the future, the research team tends to expand the topic to other research areas such as the South East or North Central Coast. The results will compare with the development of the provinces in the SCC in this study.

\section{Acknowledgements}

The authors are immensely grateful to staffs from VNU University of Science, Hanoi, Vietnam for their support and assistance with data collection and processing. This study is supported by the project No BĐKH.23/16-20.

\section{References}

[1] A.R. Romeiro, Sustainable development: an ecological economics perspective, estudos avançados 26 (2012) 65-92. http://dx.doi.org/10. 1590/S0103-40142012000100006.

[2] E.D. Bidone, L.D. Lacerda, The use of DPSIR framework to evaluate sustainability in coastal areas. Case study: Guanabara Bay basin, Rio de Janeiro, Brazil, Regional Environmental Change 4 (2004) 5-16. https://doi.org/10.1007/s10113003-0059-2.

[3] A.A. Cissé, F. Blanchard, O. Guyader, Sustainability of tropical small-scale fisheries: Integrated assessment in French Guiana, Marine Policy 44 (2014) 397-405. https://doi.org/10. 1016/j.marpol.2013.10.003.

[4] H.M. Leslie, et al., Operationalizing the socialecological systems framework to assess sustainability, Proceedings of the National Academy of Sciences 112 (2015) 5979-5984. https://doi.org/10.1073/pnas.1414640112. 
[5] S. Kwatra, A. Kumar, P. Sharma, S. Sharma, S. Singhal, Benchmarking sustainability using indicators: An Indian case study, Ecological Indicators 61 (2016) 928-940. https://doi.org/10. 1016/j.ecolind.2015.10.049.

[6] L.T. Hai, P.H. Hai, L. Hens, Health and environmental sustainability indicators in Quang Tri Province, Vietnam, International Journal of Sustainable Development \& World Ecology 16 (2009) 77-86. https://doi.org/10.1080/13504500 902793481.

[7] P.H. Hai, P.T.T. Ha, N.M. Ha, L.T. Dai, P.V. Hoa, N.C. Huan, L.V. Cam, A system of sustainability indicators for the province of Thai Binh, Vietnam, Social indicators research 116 (2014) 661-679. https://doi.org/10.1007/s11205013-0315-x.

[8] V.T. Tinh, C.Đ. Ly, L.V. Thanh, Đánh giá tình bền vững đới bờ huyện Phù Cát, tỉnh Bình Định trong điều kiện biến đổi khí hậu, Tạp chí Khoa học và Công nghệ biển 14 (2014) 132-138. http://www.vjs.ac.vn/index.php/jmst.

[9] H. Takagi, N.D. Thao, M. Esteban, T.T. Tam, H. L. Knaepen, T. Mikami, L. Yamamoto, Coastal Disaster Risk in Southern Vietnam: The Problems of Coastal Development and the Need for Better Coastal Planning (2016), The UN Office for Disaster Risk Reduction (UNDRR).

[10] Statistical Year Book, 2016

[11] SDSN-UN, Indicators and a Monitoring Framework for Sustainable Development Goals - Launching a Data Revolution for the SDGs. Leadership Council of the Sustainable Development Solutions Network, United Nations, 2015.

[12] D. Berry, Sustainable development in the United States: An Experimental set of indicators. Interim report (1997). U.S. Interagency Working Group on Sustainable Development Indicators, Washington, D.C.

[13] Department For Environment Food \& Rural Affairs-UK. Sustainable Development Indicators. https://www.gov.uk/government/statistics/sustai nable-development-indicators-sdis, 2013 (accessed 19 November 2018).

[14] M.N. Hasan, A.H. Adnan, Sustainable development indicator initiatives in Malaysia: Novel approaches and viable frameworks. Institue for Environment and Development. Universiti Kebangsaan Malaysia, Kuala Lumpur, Malaysia, 2001.

[15] K. Swain. Sustainable Development Indicators, 2015. https://gov.wales/sites/default/files/statistics and-research/2018-12/150625-sustainabledevelopment - indicators-2015-en.pdf, 2015 (accessed 20 November 2018).
[16] P. Minister, Decision on promulgation of the set of indicators for monitoring and evaluation of sustainable development in the period 2013 2020, No. 2157 / QD-TTg, 2013.

[17] Prime Minister, Decision approving the Vietnam Sustainable Development Strategy for 20112020, No: 432 / QD-TTg, 2012.

[18] M.T. Nhuan, N.T.H. Hue, N.T. Tue, T.M. Lieu, Assessing the Adaptive Capacity of Coastal Urban Households to Climate Change (Case Study in Liên Chiểu District, Đà Nẵng City, Vietnam), VNU Journal of Science: Earth and Environmental Sciences 31 (2015) 23-35. https://js.vnu.edu.vn/EES/article/view/206.

[19] G. Bravo, The Human Sustainable Development Index: New calculations and a first critical analysis, Ecological indicators 37 (2014) 145-150. https://doi.org/10.1016/j.ecolind.2013.10.020.

[20] T.M. Parris, R.W. Kates, Characterizing and measuring sustainable development, Annual Review of environment and resources 28 (2003) 559-586. https://doi.org/10.1146/annurev. energy. 28.050302.105551.

[21] A. Cendrero, D.W. Fischer, A procedure for assessing the environmental quality of coastal areas for planning and management, Journal of Coastal Research (1997) 732-744. https://www. jstor.org/stable/4298668.

[22] N.T.M. Thu, Statistic Research on Assessment of Sustainable Development in Vietnam, Philosophiae doctor thesis in economics. Socio-economic Statistics. National Economics University, 2013.

[23] Statistical Year Book, 2014.

[24] General Statistics Office, 2017.

[25] T.V. Y, N.D. Tri, T.T. Chi, N.X. Hau, N.V. Hieu, N.V. Thinh, N.T. Tuan, J. Hennessy, Establishing a sustainable development indicator set including Economic, Social, and Environmental fields in Tay Nguyen provinces, Vietnam Journal of Earth Sciences 36 (2014) 241-251. https://doi.org/10. 15625/0866-7187/36/3/5907.

[26] Thanh Tung, Danang Front takes good care of the poor. Dai Doan Ket Newspaper. http://daidoan ket.vn/tieng-noi-co-so/mat-tran-da-nang-chamlo-tot-cho-nguoi-ngheo-tintuc427715, 2019 (accessed 16 January 2019).

[27] N.L. Vu. Transport infrastructure - Advantages of Phu Yen economic zone. Investment Newspaper. https://baodautu.vn/ha-tang-giaothong---loi-the-cua-khu-kinh-te-phu-yen-d329 33.html, 2015 (accessed 22 November 2018).

[28] VCCI. Diagram of PCI 2017. http://pci2017. pcivietnam.vn/, 2017 (accessed 09 December 2018) 